\title{
Illusory contours and size illusions
}

\author{
JOHN PREDEBON \\ University of Sydney, Sydney, New South Wales, Australia \\ (Charles W. Eriksen, sponsor)
}

\begin{abstract}
Coren (1972) found that a target placed on an illusory contour figure appears smaller than an identical target alongside the illusory figure. To assess whether this size illusion can be described in terms of the principle of size contrast, 53 subjects made relative size judgments of a target circle in an illusory square figure and in various control patterns. The results indicated that the size illusion found in illusory figures cannot be explained solely by reference to mechanisms subserving size contrast.
\end{abstract}

As shown in Figures $1 \mathrm{~A}$ and 2E, the term subjective or illusory contours refers to the perception of contours across homogeneous regions of physical stimulation. Typically, observers report that the figures defined by the subjective contours appear to stand out from and, in the case of Figures $1 \mathrm{~A}$ and $2 \mathrm{E}$, to be lighter than the surrounding surface (Helpern, 1983).

Coren (1972) reported a novel size illusion associated with illusory contour patterns. He found that a target positioned on an illusory triangle figure appeared smaller than an identical target placed on the surround. Subsequently, Porac (1978) confirmed Coren's observations with the illusory square display shown in Figure 1A.

The size illusion found in illusory figures can be explained in at least two different ways. One approach is to consider the size distortion as a by-product of the depth information contained in illusory contour configurations (Coren, 1972). According to this hypothesis, the visual system organizes a complex two-dimensional array into a structured three-dimensional representation with the illusory contours defining the edges of a surface located on a depth plane in front of the surrounding surface. Hence, if the depth information is strong enough to evoke the constancy scaling mechanism, a target located on the more distant background should appear larger than an identical target placed on the subjective figure.

A different interpretation of the size distortions is suggested by the principle of size contrast. As exemplified by the Titchener circle illusion, size contrast describes the illusory contraction or expansion of adjacent elements that differ in size; an extent appears smaller when adjacent to larger extents and larger when adjacent to smaller extents (Robinson, 1972). Hence, the size distortion found by both Coren (1972) and Porac (1978) could be due to the contrast arising from the disparity in the size of the center circle and the larger surrounding inducing ele-

The author's mailing address is: Department of Psychology, University of Sydney, New South Wales 2006, Australia. ments. The plausibility of this explanation is suggested by the finding that, when asked to indicate the relative size of the two circles in the contourless pattern shown in Figure 1C, 12 of the 15 observers reported that the circle inside the pattern appeared smaller $(p=.079$, binomial test).

In the present study, the size contrast explanation was evaluated using the five patterns shown in Figure 2. Subjects were required to make relative size comparisons of the circles according to the method of paired comparisons. The contourless (Figure $2 \mathrm{C}$ ) and subjective square (Figure 2E) patterns constituted the critical pair of stimuli. For this stimulus pair, the size contrast explanation of the size distortions found in illusory figures is invalidated if there is a tendency for observers to report a difference in the apparent size of the two circles. Striped-disk (after Kanisza, 1974), rather than solid-disk, inducing elements were used, since only minimal configurational alterations of the subjective square pattern are required to form the contourless control pattern. Porac (1978) found that size distortions are absent in objective contour arrays (Figure 1B). However, since informal observations indicated that a size illusion is present in Figure 1B, Figures 2B and 2D were included in the present study to evaluate Porac's claim that size illusions do not occur in patterns containing physically present contours.

\section{METHOD}

\begin{abstract}
Stimuli
The stimuli were the 10 possible pairings of the five patterns shown in Figure 2. Each pair was drawn separately on $21 \times 29.5 \mathrm{~cm}$ sheets of white paper, with the pairs positioned in a left-right arrangement. The diameters of the striped inducing elements were $1.2 \mathrm{~cm}$, and the sides of the subjective and objective squares were $2 \mathrm{~cm}$. The diameters of the test circles were $.3 \mathrm{~cm}$, and the separation between the midpoints of the test circles in each stimulus pair was $3.5 \mathrm{~cm}$. The test field was a white square cardboard $(60-\mathrm{cm}$ side) that was attached to, and rested on, the surface of a table. The stimulus cards were positioned underneath a square (17-cm side) aperture in the test field. The standing subject with chin resting on a chinrest viewed the patterns from a distance of approximately $60 \mathrm{~cm}$ under normal fluorescent room illumination.
\end{abstract}



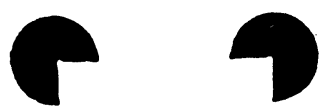

A

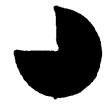

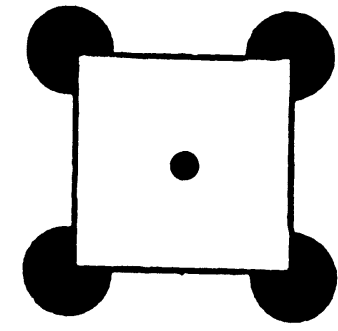
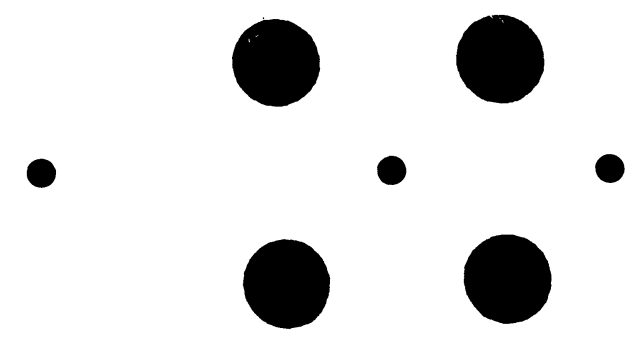

$\because$

B

C

Figure 1. (A) Illusory contour square pattern. (B) Objective contour square pattern (Porac, 1978). (C) Contourless or control pattern.
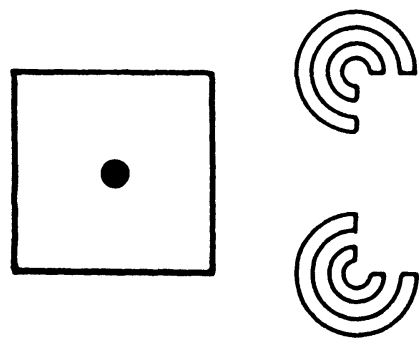

B
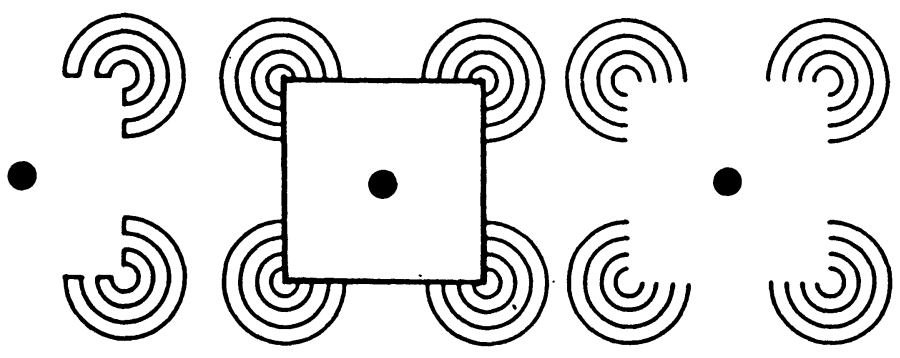

A
C
D
$\mathbf{E}$

Figure 2. Experimental stimuli.

\begin{abstract}
Subjects and Procedure
The sequence of presentation of the 10 pairs of stimuli followed the guidelines proposed by Ross (1934) for the method of paired comparison. The position (left-right) of the stimuli was balanced across subjects, and each subject received a different order of presentation. Half the subjects were instructed to indicate, by raising either the left or the right hand, which of the two circles appeared smaller, whereas the remainder indicated which of the two appeared larger. Judgments were made within a 10 -sec period.

Since not all naive observers experience the subjective contour illusion (Parks, 1984), at the completion of the experiment the subjects were shown Figures 2C and 2D without the test circles and were asked to describe the patterns. Adopting as the criterion for experiencing the illusion the lightness enhancement of the area inside the inducing elements, four subjects failed to notice the illusion, one subject claimed that the illusion occurred in both the subjective and the contourless patterns, and two subjects reported not seeing the illusion during the presentations of the stimuli. These six observers were not included in the final sample of 52 subjects, all of whom were students enrolled in an introductory course in psychology.
\end{abstract}

\section{RESULTS AND DISCUSSION}

The data, expressed as the proportion of times the circle in one figure was judged larger than the circle in another figure, appears in Table 1. By adopting the procedure outlined in Guilford (1954), a scale of perceived size can be derived from these data. The proportion scores are converted to $\mathrm{z}$ scores, and the $\mathrm{z}$ scores for each column are summed and averaged to give the scale values shown in the row labeled Mzjk of Table 1. The Rjk scale values are the linearly transformed Mzjk scores obtained by assigning the value zero to the lowest Mzjk score. The $\chi^{2}$ test carried out on the expected and obtained proportions was not significant $\left[\chi^{2}(6)=4.97, p>.05\right]$, indicating that the assumptions of Case 5 of the law of comparative judgment were satisfied by the data. Consequently, the $\mathrm{Rj}$ values in Table 1 can be interpreted as representing the location of the five stimuli on the scale of perceived size. These values indicate that a size illusion occurred in all four patterns; relative to an unenclosed circle (Stimulus A), observers tended to underestimate the size of the test circles in the patterns (Stimuli B, C, D, and E).

Table 1

Proportion Matrix for the Five Stimuli Shown in Figure $2(\mathbf{A}, \mathbf{B}, \mathbf{C}, \mathrm{D}, \mathrm{E})$

\begin{tabular}{lllllll}
\hline & & \multicolumn{5}{c}{ Stimuli k } \\
\cline { 3 - 7 } & & $\mathrm{a}$ & $\mathrm{b}$ & $\mathrm{c}$ & $\mathrm{d}$ & $\mathrm{e}$ \\
\hline \multirow{4}{*}{ Stimuli j j } & $\mathrm{a}$ & & .750 & .769 & .712 & .808 \\
& $\mathrm{~b}$ & & & .577 & .635 & .673 \\
& $\mathrm{c}$ & & & & .615 & .712 \\
& $\mathrm{~d}$ & & & & & .635 \\
& Mzjk & -.568 & -.048 & .016 & .170 & .521 \\
& $\mathrm{Rj}$ & 0 & .520 & .584 & .738 & 1.089 \\
\hline
\end{tabular}

Note-The values in the matrix denote the proportion of times stimulus $j$ was judged larger than stimulus $k . M z j k$ and $R j$ are the pairedcomparison scale values. 
The occurrence of a size illusion in the objective-square condition (Figure 2D) contradicts Porac's (1978) finding that size distortions are absent in the objective contour pattern shown in Figure 1B. In order to determine whether Porac's findings are specific to patterns containing solid inducing disks, a second experiment, using the patterns shown in Figure 1, was conducted on an independent sample of subjects $(\mathrm{N}=26)$. The dimensions of these patterns and the experimental procedure were identical to the main experiment. The linearly transformed scale values derived from the paired comparison judgments were $.912, .523, .371$, and 0 for the illusory square (Figure 1A), objective contour square (Figure 1B), contourless pattern (Figure 1C), and an unenclosed circle, respectively. Clearly, this pattern of scale values confirms the results of the main experiment.

The claim that the size distortions in illusory figure patterns can be explained solely by reference to mechanisms subserving size contrast is not supported by the present findings. Instead, the different scale values for the illusory and contourless stimuli (Figures $2 \mathrm{C}$ and $2 \mathrm{E}$ ) suggest that additional or different factors need to be invoked to account for the magnitude of the size distortion occurring in illusory figure configurations.

Employing the "Pandora's box" principle for measuring perceived depth in two-dimensional displays (Gregory, 1966), Coren and Porac (1983) found that, relative to the background, the figure in illusory contour patterns is perceived as being closer to the observer. A similar, although smaller, depth effect was obtained for a control pattern with real contours. These results lend credence to the view that the segregation of the figure and background into separate depth planes contributes to the size distortion as a consequence of the constancy scaling mechanism evoked by the depth information present in the displays. Interestingly, if it is assumed that the magnitude of the size distortion indexes the relative saliency of the depth information in the patterns, the lower scale value for the objective than for the illusory square conditions (Figures 2D and 2E) is consistent with Coren and Porac's finding of a differential depth effect in objective and illusory contour displays.

\section{REFERENCES}

Coren, S. (1972). Subjective contours and apparent depth. Psychological Review, 79, 359-367.

Coren, S., \& Porac, C. (1983). Subjective contours and apparent depth: A direct test. Perception \& Psychophysics, 33, 197-200.

GrEGory, R. L. (1966). Visual illusions. In B. Foss (Ed.), New horizons in psychology. Baltimore: Penguin Books.

GuIlFoRd, J. P. (1954). Psychometric methods. New York: McGraw-Hill.

HALPERN, D. F. (1983). The multiple determination of illusory contours: 1. A review. Perception, 12, 281-291.

KANISZA, G. (1974). Contours without gradients or cognitive contours? Italian Journal of Psychology, 1, 93-113.

PARKs, T. E. (1984). Illusory figures: A (mostly) atheoretical review. Psychological Bulletin, 95, 282-300.

Porac, C. (1978). Depth in objective and subjective contour patterns. Bulletin of the Psychonomic Society, 11, 103-105.

Robinson, J. O. (1972). The psychology of visual illusion. London: Hutchinson University Library.

Ross, R. T. (1934). Optimum orders for the presentation of pairs in the method of paired comparisons. Journal of Educational Psychology, 25, 375-382.

(Manuscript received for publication September 24, 1984.) 